\title{
Analysis And Measurement Of The Impact Of Information Technology Investments On Performance In Mexican Companies: Development Of A Model To Manage The Processes, Projects And Information Technology Infrastructure And Its Impact On Profitability
}

Ricardo Sierra Martínez, Universidad Anáhuac del Sur, Mexico Carlos Miguel Barber Kuri, (E-mail: carlos.barber@anahuac.mx), Universidad Anáhuac del Sur, Mexico

\begin{abstract}
In Mexico, companies invest enormous resources in information technology (IT), with little evidence of the latter's effectiveness. Company directors struggle with gauging how effective or ineffective making these investments truly is, given the lack of instruments of measurement by which to establish, for instance, an internal rate of return or a period of recovery on investments. There is also no evidence by which to link IT investment to improvements in a company's performance or profitability. While several American and Australian universities have developed studies that address these issues, for the most part these are limited to their respective countries and in some cases to Canada and Europe. Thus, there is a lack of empiric evidence in the Mexican scenario. Being able to analyze and measure the impact of IT investments is an important first step into making these resources more efficient. Based on the following analyses, one will identify the variables that intervene in successful and/or unsuccessful management of processes and projects, as well as in the administration of IT infrastructure.
\end{abstract}

\section{INTRODUCTION}

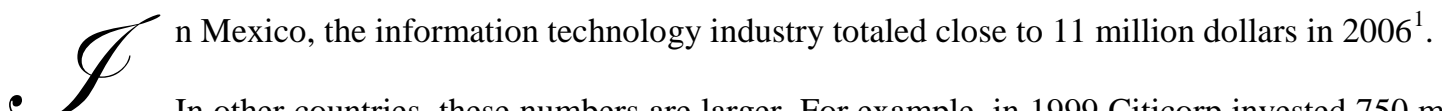

In other countries, these numbers are larger. For example, in 1999 Citicorp invested 750 million dollars in a new global database. In Mexico, during the last few years, an insurance company has spent over 150 million dollars on a new integral information system. The results of these investments are not always what executives anticipate, prompting debate on whether to continue funding such resources to IT infrastructure, processes and projects. The favorable impact that these investments have on performance is not necessarily evident; however, it is a fact that globalization is creating tremendous demands on companies to share information internally and externally, by which it is obvious that companies require an information technology infrastructure in order to continue competing on the global market, which requires more investments of this rubric.

\footnotetext{
${ }^{1}$ Cf. Espinosa, Susana. (2006) “Industria TIC: Mercado de TI. Resultados del 2006”. Select de México. www.select.com.mx
} 
A company's information technology capacities can limit or enhance the ability to respond to market conditions (Davenport and Linder, 1993). New technological infrastructures enhance the creation of new forms of organization, and in the process, also create a complex environment that on the one hand increase the demand for cost-control standardization and on the other stimulate the demand for innovation in order to respond to client demands. Most companies are not capable addressing this dual requirement ${ }^{2}$.

Thus, we find ourselves in a complex decision-making scenario since there is a need to invest in IT infrastructure, processes and projects in order to render companies competitive despite the lack of measurements for the (un)successful impact on company profitability that these investments have. For the Mexican setting the situation is even more uncertain, due to the fact that the studies that have been generated are very focused to American enterprises, which channel much larger sums when compared to their Mexican counterparts, both in absolute values (consider Citicorp's 750 million dollar investment) and in terms relative to sales.

Through its "Center for Information Systems Research" (CISR) of the Sloan School of Management, universities such as MIT (Massachusetts Institute of Technology) have as their mission finding how companies generate value through Information Technology. For 2006, investigation centered on three categories: 1) Managing of IT Resources, 2) IT and Business Strategy; and 3) IT Management Abroad. Likewise, University of Michigan, through the Stephen M. Ross School of Business and its "Business Information Technology" focus, has published reported interesting research such as "Effect of Information Technology on Customer Satisfaction: Theory and Evidence" (Mithas and Krishnan, 2006) and "The Value of IT Business and its Effects on the Industry: The Role of a Competitive Environment", among others.

This article addresses the fact that in Mexico no studies have been conducted in order to evaluate the impact of information technology on organizations, resulting in the unproductiveness of invested resources.

Company executives worry about the investments they feel compelled to make in information technology. Yet year after year the budgets assigned to IT areas are considerable. In some periods, these investments rise considerably if there has been proper budgeting and planning and/or execution of IT-related projects.

With respect to IT projects, there is evidence that an important percentage of these ventures are not successful $^{3}$. IT Cortex ${ }^{4}$ reports that companies such as Robbins-Goia, KPMK Canada and Standish Group, among others, have shown failure levels that surpass $50 \%$ of the total initiatives. There are many causes for these results, which for the moment will not be analyzed; however the central theme is the level of client dissatisfaction for these projects. Some examples of this situation follow:

- $\quad$ According to the Robbins-Goia ${ }^{5}$ survey (2001), 51\% of ERP (Enterprise Resource Planning) ${ }^{6}$ implementations have not been successful.

- $\quad$ According to a KPMG Canada ${ }^{7}$ study (2001), 47\% of IT projects failed: over three fourths of these surpassed their expected timeframe in $30 \%$ or more; over half of these projects exceeded their budgets in a significant manner.

- $\quad$ According to Standish Group $^{8}$, through its Chaos Report (2001), 31\% of IT projects are cancelled before they have concluded; $52.7 \%$ will cost $189 \%$ more than their original budgets. Seen from a successful perspective, on average $16.2 \%$ of software projects end on time and budget; in large companies, these numbers are worse: only $9 \%$ of these projects finish on the allocated timeframe and budget.

\footnotetext{
${ }^{2}$ C.f. Ross, Jeanne Y Rockart, John (1999). “Reconceptualizing IT”. ”, Sloan Management Review (302), p. 2.

${ }^{3}$ A successful project is defined as one which produces the expected results on an adequate timeframe and respecting the approved budget.

${ }^{4}$ Ref: IT Cortex (2001). "Failure Rate. Statistics over IT projects failure rate"

${ }^{5}$ Ref. IT Cortex (2001). Ibid

${ }^{6}$ ERP Enterprise Resource Planning. This is a reference to software systems that compress into a single application the information in distinct areas of a company, typically Accounting, Inventory, Sales, Purchases, Invoices, etc.

${ }^{7}$ Ref. IT Cortex (2001). Ibid

${ }^{8}$ Ref. IT Cortex (2001). Ibid
} 
- $\quad$ After a series of investigations, IT Cortex ${ }^{9}$ has determined the following:

$\circ \quad$ IT projects are more likely to fail than to succeed

$\circ \quad$ Only 1 out of 5 IT projects will satisfy its client base

$\circ \quad$ The bigger the project (and its respective investment), the larger the failure.

With respect to investments in IT Infrastructure, the reported numbers are also in the millions. For instance:

- $\quad$ Travelers Insurance ${ }^{10}$ replaced its broad, expansive but outdated voice and data communications network for a newer version with state of the art, high-speed lines;

- Johnson \& Johnson ${ }^{11}$ broke an administrative management tradition by compromising corporate funds in order to help operative enterprises acquire desktop equipment;

- $\quad$ Statoil ${ }^{12}$ gave its 15,000 employees state of the art computers for home and office use.

As with these projects, infrastructure investments have not been as profitable as expected. The impact of these ventures on profitability is not at all clear, while the demands for greater infrastructure investments increment each day.

\section{PROBLEMS IN ORGANIZATIONS RELATED TO INVESTIGATION}

The possibility of counting with a model that measures the impact of information technology investments over fundamental parameters in the administration of a company as operative performance and profitability.

It will also be important to find those variables that determine these positive or negative effects, in order to generate a model that allows companies to obtain better results in the management of Information Technology which includes processes, projects and infrastructure.

\section{Justification Of The Research That Addresses This Article}

- Mexican companies invest copiously in IT, with close to $\$ 11,000$ million dollars in 2006. However, the productivity and benefits of these investments remains unclear. It is imperative to be able to measure and establish the relation of these investments to the company's operative yield and profitability.

The lack of a model by which to guide companies towards better results in IT investment, especially for mid-sized Mexican companies, provokes a constant uncertainty with respect to over investing, securing a competitive edge, or even ceasing investments in order to survive in a competitive and globalized market.

\section{Investigation Objectives}

- $\quad$ Main Objective

- To prove that it is possible to measure the impact that investments in IT infrastructure, processes and projects generate over companies operative performance and profitability.

- To generate a model that allows for quick and efficient management of information technology processes, projects and infrastructure in large and medium-sized firms with the objective of making investment profitable in these rubrics.

\footnotetext{
${ }^{9}$ Ref. IT Cortex (2001). Ibid

${ }^{10}$ C.f. Ross, Jeanne y Rockart, John (1999) “Reconceptualizing IT”. ”, Sloan Management Review (302), p. 3

${ }^{11}$ C.f. Ross, Jeanne y Rockart, John (1999). Ibid.

${ }^{12}$ C.f. Ross, Jeanne y Rockart, John. (1999) Ibid.
} 
- $\quad$ Specific Objectives:

- Analyze proposed variables to gauge the impact of IT investments generate in parameters such as customer satisfaction, agility to respond to change, processes improvement and in profitability.

$\circ \quad$ Evaluate the most significant operational definitions and instruments that have been developed in order to measure TI efficiency levels.

\section{Questions Related To Research}

- Is it possible to measure the impact of investment in information technology in operational performance and profitability of Mexican companies?

- Is there a significant and relevant effect in a company's performance following IT investments?

- What is the nature of the relationship between the levels of IT investment and a company's performance? Does greater investment equal greater profits? Is there a level of optimal investment that produces a better performance, but when continued produces negative results? ${ }^{13}$

- What factors are influential in increasing the probability of success in information technology projects?

- What are the variables that are negatively affecting projects? What caused such poor performance?

- $\quad$ Is it possible to predict the effect of a particular IT investment in companies' performance?

- How do companies currently calculate their returns on IT investment?

- Is it possible to generate an effective short, medium, and long-term investment model for infrastructure, process and project related to information technology?

- What are the practices that companies follow nowadays in the management of their IT processes, projects and infrastructure?

\section{FRAME OF REFERENCE}

\section{Managing Investment In Information Technology ${ }^{14}$}

While businesses invest significant resources into information technology (IT), there is very little evidence to link IT investment with company performance. It is imperative to understand the causes by which IT investments originate; it is also important to define what IT is for the purpose of determining investment levels, how to monitor these investments and what other factors influence in investment decision-making.

Three significant implications face those responsible for IT investment decisions:

- The need of adopting an accepted definition of what IT represents and its tracking throughout time, against a conveniently defined base.

- $\quad$ The need of separating different types of investment and matching these with organizational performance measurements.

- The need of taking into consideration other organizational factors, such as upper management obligation and previous systems experience.

Although it is very tempting to conclude that IT investments increment company organizational performance, there is still very little evidence to confirm such an assessment.

Frequently, company directors only have the competition's investment models (based on sales percentages or the increment in the past year's budget) as cost guides. Unfortunately, most investment is purely based on blind faith in future positive yields.

\footnotetext{
${ }^{13}$ Cf. Weill, Peter; Olson, Margrethe (1999). "Managing Investment in Information Technology: Mini Case Examples and Implications". MIS Quarterly, Mar 1999.

${ }^{14}$ Cf. Weill, Peter; Olson, Margrethe (1999). Ibid.
} 
Information technology is essential in business, but inappropriate guides are used to determine adequate investment levels.

\section{The Problem.}

The main problem is: What is the impact of IT investment levels in company performance? This is a complex theme, as IT investment is one of several factors that affect an organizations performance (Lucas, 1975; Turner, 1985). The main issue is whether IT investment actually makes a difference.

\section{IT Investment Metrics}

Some studies have utilized a variety of metrics for IT investment levels.

The Diebold Group (1984) has consistently made use of three metrics:

- $\quad$ Information systems budget as a sales percentage

- $\quad$ Systems staff as a percentage of the total staff

- $\quad$ Expenses coefficient in hardware relative to personnel expenditures

Datamation (1986) has used the information systems budget metric as a percentage of sales. Bender (1986) made use of the IT investment coefficient in relation to premium income in the insurance industry. Stressman (1985) refined the metric for it to be a fraction of the management costs assigned to IT. He believed that management's base expenses serve as a more appropriate than income measure, given that that it is more influential to administrative decisions.

In a study on the banking industry, Turner (1985) used other metrics, including "costs relative to DP (data processing)" and the number of functional areas that counted with computational applications.

All these approaches have advantages and disadvantages. None of them totally resolve the problem.

Throughout time, even the use of a same metric (budgeting IT as a sales percentage), resulted in differing results for the above-mentioned research companies:

- $\quad$ Datamation (1986) established a factor of 0.57

- $\quad$ Diebod (1984) established a percentage between 0.9 and 1.0

- Starassman (1985) found a percentage of 2.0; in the government sector, 1.2 of the total budget

Panko (1982) found that on average, companies spent $\$ 3,000$ dollars a year per worker.

The disparity in results reflects the differences in defining and measuring IT investment. A comparison of these investment definitions between companies only serves as a very general guide. Investment percentages were taken out of the context of the company's strategy.

\section{Performance Measurements.}

Determining performance is highly problematic in this type of investment. A variety of economic and social measures can be adopted to this end (Zammuto, 1982).

One approach is to establish a singular global performance measure. In a study of the insurance industry, Bender (1986) made use of the IT expense coefficient in relation to premium income. Another approximation used by several analysts is that a single measure does not capture all the factors that contribute to performance, and consequently the use of such a measure is relatively arbitrary (Turner, 1985). 
In a study on the impact of IT investment on a group retail companies' financial performance, Cron and Sobol (1986) made use of the following four metrics:
- $\quad$ Profit before taxes
- $\quad$ Return on assets
- Returns on net utility
- $\quad$ Five-year growth rates

Other performance measures include market share (PIMS Program, 1984) and the net operative equity coefficient in relation to total assets (Turner, 1985).

Given the complexity of organizational yield measurements, it is clear that a single criteria is not sufficient and that a number of yet undefined measurements are required.

\section{The Relationship Between IT Investment And Performance.}

In a study of 58 banks, Turner (1985) concluded that "unexpectedly, no relation was found between organizational performance and the relative proportion of resources assigned to data processing".

Bender (1986) divided IT investment in components and found that only expenses on personnel, hardware and infrastructure had a significant impact on performance. In his study, software investments did not prove significant. Bender concluded that the insurance industry features an optimal level of investment for information processing. Companies that invest below this level perform poorly, while firms that invest above this level incur in unnecessary expenses.

Cron and Sobol (1983) found that companies in the retail industry that made extensive use of computers either had very poor or very satisfactory financial yields. It was determined that those firms that featured a superior strategic position increased productivity three times more than companies with an inferior strategic position. The study concluded that if a company employed a superior strategic stance, IT investments improved performance, while those companies with a weak strategic position suffered from less effective IT investments.

A study of 40 insurance companies (Harris and Katz, 1988) revealed that the more profitable companies spent a significantly higher percentage on IT than their less successful counterparts.

These conflicting results are of little use for those that day to day conduct decisions on IT investment. Nevertheless, there are three areas that are useful for more effective investment management:

\section{Areas Of Interest In The Investment Measurement}

- Define and track IT. - given that IT plays an increasingly important role in organizations, defining what is IT and monitor expenses becomes a crucial activity. Organizations have different definitions for IT; however, there is a tendency to confirm this definition.

- IT Investment and Returns. - The problem of determining the returns on IT investment is complex; most studies and their results have failed to convince company directors. Much investment was made with the expectation of a real return; however, there is little evidence to support these assumptions.

- Organizational Situations. - It investment is insufficient. Investment must produce useful outcomes (services). An important number of organizational situations have been identified as influential elements in these outcomes, including the directives' willingness to make investments and align these with company strategy. 


\section{Recommendations For Each Area}

\section{Defining And Tracking IT.}

The firsts step in administrating IT is to know exactly what the investment is. As measuring and tracking investments is difficult, the following is suggested:

- Adopting a definition of what IT is, including all hardware, software, personnel and communications, administrative and indirect expenditures related to IT areas, training and maintenance.

- $\quad$ Measuring and tracking this expenditure over time against a convenient base. This base can be sales, total expenditures, or administrative expenses (Stassmann, 1985). It is also important to capture all the decentralized expenses of all functional departments.

The fact by which IT investments are immersed in company strategies can be taxonomized under three categories: strategic, informational and transactional (Turner and Lucas, 1985).

- $\quad$ Strategic IT is defined as the IT that changes a company's product/service or the manner in which an organization competes in a particular industry (Ives and Learmonthe, 1984) and can commonly be identified as an IT investment aimed at increasing sales. Usually this is a long-term investment.

- Informational IT provides information for organization's decision-making and communication infrastructure. Investments in computational resources for planning, producing, monitoring and improvement are included. This tends to be a medium-term investment.

- $\quad$ Transactional IT supports operative management; it is characterized by repetitiveness, and is associated with short returns on investment. Normally this involves the processing of repeated transactions, as in purchase order processing or accounting. Investments in transactional IT can be defined as those that intend to reduce expenses.

A fourth category emerges in the form of threat-induced IT investment. This kind of investment is undertaken in order to compete within a certain industry. Returns on this kind of investment tend to be smaller and of a different nature than the above-mentioned, since threat-induced IT investment is short-term and mandatory in order to compete. Thus, it cannot be linked to returns over real investment. Therefore, this type of investment can be considered a sunk expense and is consequently difficult to justify.

It is recommended that companies classify their investments according to these four categories and then track on these for an extended period of time. This approach reaffirms the need for aligning company strategy with IT investment.

\section{IT Investment And Return}

Justifying IT investment is a real problem for most organizations. Return Estimates on Investment (ROI Return on Investment) and other capital valuation techniques do not apply to most IT investment for the following two reasons:

- It is very difficult to determine the initial cash flow particularly in IT investments executed for strategic reasons. Due to this, estimates of return on investment are not possible.

- $\quad$ IT investments tend to be dominant throughout organizations and the consequences of investment appear to be the result of interactions between different projects and distinct investments in infrastructure (databases, hardware, software, etc.) 
It is necessary to establish an approach throughout the entire organization in order to determine the relationship between IT investment and organizational performance. One suggests:

- Recognizing which return on investment estimates is irrelevant to IT investment. The exception being the inversion of transactional IT, where one finds the objective of reducing costs by substituting labor for capital.

- $\quad$ Recognizing if a threat-induced investment is necessary in order to compete in an industry; confronting this threat could produce a negative result, but it is essential to the company's survival.

- Much of IT investment, particularly of the strategic kind, is executed on instinct rather than on solidly sustained reasoning. For this type of investment, companies need to measure, follow up and attempt to determine its effect on organizational performance.

There exist a number of important performance metrics for organizations. It is suggested to combine these metrics in order to measure the distinct impact attributed to IT investment in distinct aspects of organizational performance. The fine point lies in deciding whether one can logically link metrics to performance objectives for each kind of investment, as follows:

Table 1: Type of Investment vs. Performance Measurement

\begin{tabular}{|c|c|}
\hline Type of Investment & Performance Measurement \\
\hline Strategic & Reasons for Sales Increase \\
\hline Informational & Return on Actives \\
\hline Transactional & Indirect Labor \\
\hline
\end{tabular}

Source: Weill, Meter; Olson, Margrethe (1989)

Performance measurements for each type of IT investment square up with the each investment's objective and duration, as demonstrated:

- $\quad$ Strategic IT investments are generally realized on a long-term basis and are related to competitive advantages. To reach this objective, it is suggested to further examine the reasons behind sales growth.

- Informational IT investments are normally realized as medium-term ventures in order to improve decisionmaking processes. To attain this goal, it is suggested to use the Returns on Assets metric.

- $\quad$ Transactional IT investments are usually realized with the objective of reducing operational costs by replacing labor for capital. To achieve this goal, it is suggested to measure changes in non-productive labor (indirect).

The objective is to follow up not only on IT investments (by type) but also on the appropriate measurements of organizational performance throughout time, and to find tendencies and patterns. This process will facilitate establishing the link between IT investments with business strategies. It will also render general directrices in search of associating IT investment with corporate return.

\section{Organizational Situations} investments.

Generally speaking, one can identify four organizational components that affect the effectiveness of IT

- $\quad$ IT Obligations to upper management

- $\quad$ Companies' previous experience with IT

- User satisfaction with systems

- Turbulence of an organization's political environment 
One must be aware of these four components when conducting significant IT investments. All four appear consistently in implementation literature. Furthermore, it has been determined that just the aggregation of one of these four components significantly modified the performance of 33 companies in the manufacturing industry (Weill, 1988).

\section{APPROACHES AND TYPES OF INVESTIGATION}

According to Hernández, Fernández y Baptista (2006) investigation can have more than one focus. This is the case of the research that is hereby proposed.

Research is always initiated with an exploratory focus, every time one inquires about a subject from a new perspective. In this case the position of Mexican companies requires contextualizing the Mexican reality and attempting to adapt to what these business can recover.

Research should then take upon a correlational focus, which will seek to establish the relationship between information technology investment and important company parameters, such as operative performance and profitability, which are generated as a result of these investments.

Initially research will be of a qualitative nature due to the previously discussed exploratory approach, and only later will it become quantitative since it will be based on empirical generalizations applicable to the study's problem (for the most part these proposals have been proven true in previous studies (Hernández et al., 2006)). Therefore, investigations are characterized by a deductive nature, which compares initial conclusions to current approaches in the field of research.

\section{Capabilities And Limitations}

Table 2: Research Capabilities and Limitations

\begin{tabular}{|l|l|l|}
\hline \multicolumn{1}{|c|}{ Research Concept } & \multicolumn{1}{|c|}{ Included Factors } & \multicolumn{1}{c|}{ Excluded Factors } \\
\hline Application boundaries. & Mexico. & Abroad. \\
\hline Type of company. & Firms that require IT to be more competitive. & $\begin{array}{l}\text { Firms that due to their size and structure do not } \\
\text { benefit competitively from IT. }\end{array}$ \\
\hline Size of company. & Medium and large businesses. & Small and micro businesses \\
\hline $\begin{array}{l}\text { Fundamental elements in } \\
\text { field research. }\end{array}$ & $\begin{array}{l}\text { Company profitability and operative } \\
\text { performance measurement as a result of IT } \\
\text { investment }\end{array}$ & Macro and micro economic aspects. \\
\hline
\end{tabular}

Source: Sierra, Ricardo (2006).

\section{Main Hypothesis And Work Hypothesis}

\section{Main Hypothesis}

If companies learn to measure the impact of information technology investment on their performance metrics, then these will be more efficient.

Work Hypothesis

- The lack of an operative model reflective of a company's strategy results in IT responses to executives' demands.

- $\quad$ The lack of a process for project management and the formalized training of project leaders results in IT projects having a higher probability of failure than success. 
Dependent and Independent Variables

Table 3: Dependents and Independents Variables

\begin{tabular}{|l|l|}
\hline \multicolumn{1}{|c|}{ Dependent } & \multicolumn{1}{|c|}{ Independent } \\
\hline Y1 - Profitability as a result of IT investment & X1 - IT investment \\
\hline & X2 - Uniform definition of what IT encompasses \\
\hline & X3 - IT processes \\
\hline & X4 - IT projects \\
\hline & X5 - IT infrastructure \\
\hline & X6 - Industry in which companies operate \\
\hline & X7 - Level of upper management commitment \\
\hline Y2 - Operative Performance as a result of IT investment & $\mathrm{X} 8$ - IT personnel linkage to administrative processes \\
\hline Source SIERRA, Ricardo $(2006)$ & \\
\hline
\end{tabular}

Source: SIERRA, Ricardo (2006).

\section{INVESTIGATION DESIGN}

\section{Design}

The process begins with a survey of relevant literature. As has been mentioned, there are two important research centers in the United States dedicated to this topic: the Center for Information Research at the Massachusetts Institute of Technology's Sloan School of Management and the Stephen M. Ross School of Business at the University of Michigan.

The author of this study, a Ph.D candidate in Management at the Universidad Anáhuac México Sur, has twenty years of experience in the information technology industry with which to contribute to this study's findings.

Given that most studies are still geared towards companies in the United States, Canada and Europe, the judgment of experts in Mexico will be essential to developing the model being proposed.

A first evaluation will be carried out through company surveys, which will identify IT-related variables with positive or negative impacts on business performance and profitability. Based on these results, expert-led feedback sessions will be conducted in order to make the necessary adjustments to the afore-mentioned surveys and initial design stages.

Subsequently, a model capable of measuring the impact of investment (with the previously discussed parameters) will be designed and then applied to participating businesses. Likewise, companies in the service sector will be sought out, in order to apply a management model for IT processes, projects and infrastructure.

The next step will consist of evaluating the effectiveness of the model, with the possibility of making further adjustments. With the results of these observations, a thorough analysis of the information will be carried out in order to test the main and alternative hypotheses.

Finally, conclusions and recommendations will be drafted. 
Figure 5. Research Design
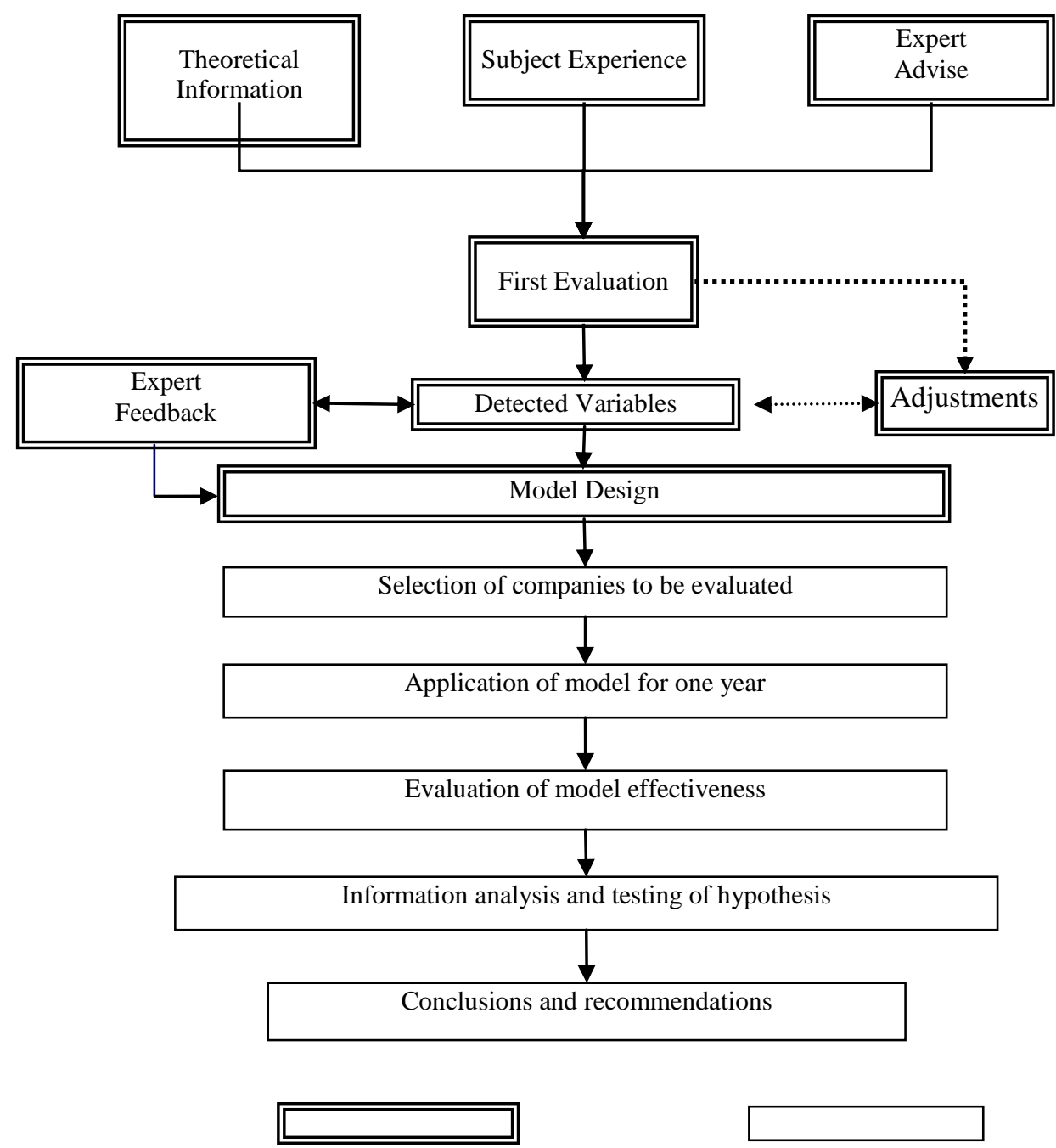

Exploratory Research

Field Work

Source: Sierra, Ricardo (2006)

The result of this first stage leads us to the second stage of investigation where a Panel Type Longitudinal Design (soon to be described) is employed for fieldwork.

\section{Data Collection}

A Panel Type Longitudinal Design will be used to collect data.

- Invitations to participate in the investigation will be extended to several companies in the service sector.

- An initial observation will be conducted in order to understand how IT processes, projects and infrastructure are managed, searching for variables of greatest positive/negative impact.

- A model will be designed in order to measure the impact of investment and generate a more efficient administration of IT processes, projects and infrastructure.

- $\quad$ The model's results will be analyzed.

- $\quad$ Validating the main and work hypotheses is expected. 
Quasi - experimental design with intact groups of chronological series with treatment and stimulus.

Figure 6. Data Collection

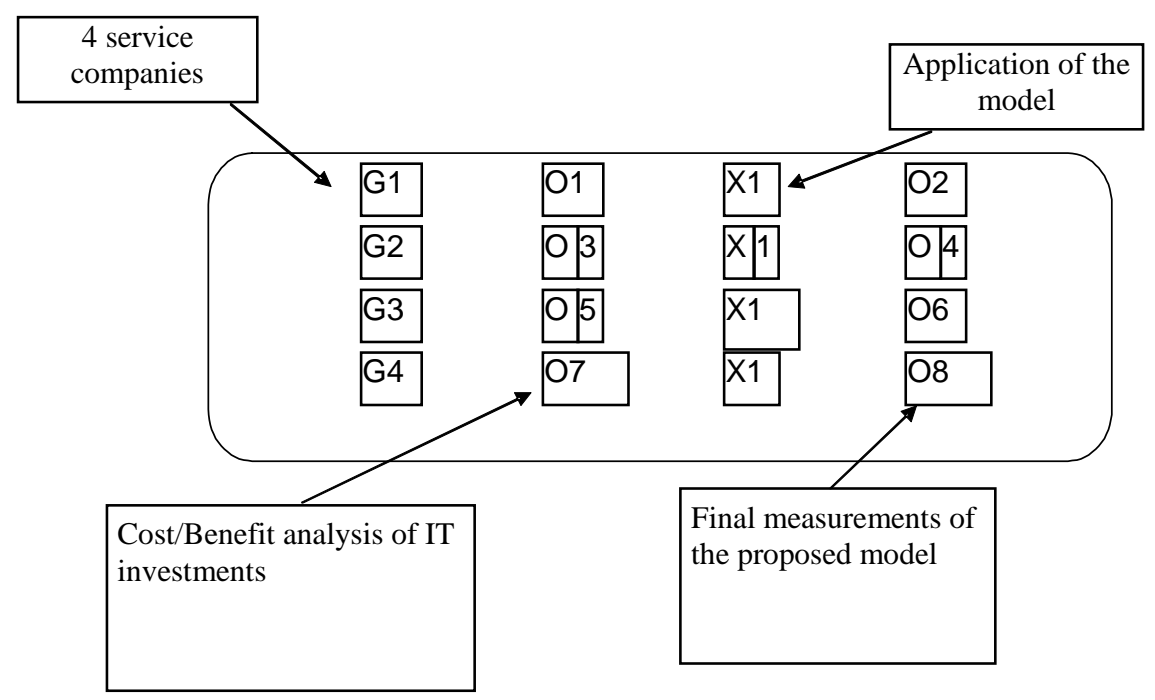

\section{EXPECTED RESULTS}

The expected results of the investigation are as follow:

- A model that analyzes and measures the impact information technology investments have on company performance and profitability.

- A model that manages information technology processes, projects and infrastructure in an effective and efficient manner, with the objective of making IT investment more profitable.

- Analysis and measurement of profitability and improved performance generated (or not) as a result of investments in technology information -in at least four Mexican companies in the service sector.

- Analysis and measurement of improvement in the management of information technology processes, projects and infrastructure as a result of the generated model in at least two service sector companies.

- Clear results and conclusions based on the investigation's findings.

\section{BIBLIOGRAPHY}

1. Bender, D. Financial Impact of Information Processing, Journal of MIS (3:2), summer 1986, pp. 232-238.

2. Cron, W. And Sobol, M. The Relationship Between Computarization and Performance: A Strategy for Maximizing Economic Benefits of Computerization, Information and Management (6), 1983, pp. 171-181.

3. Datamation. Data Processing Budget Study, Datamation, New York, 1986.

4. The Diebold Group. MIS / Telecommunications Budgets and Key Indicators, The Diebold Group Inc., New York, 1984.

5. Davenport, T.H. And Linder, J. Information Management Infrastructure: The New Competitive Weapon?, Ernest \& Young Center for Business Innovation, Working Paper CITA33, October 1993.

6. Harris, S.E. And Katz, J.L. Profitability and Information Technology Capital Intensity in the Insurance Industry, in Proceedings of the Twenty-First Hawaii International Conference on Systems Sciences, Vol. IV, January 1988, pp. 124-130. 
7. Hernández, Roberto., Fernández, Carlos y Baptisa, Pilar. Metodología de la Investigación. (4 ${ }^{a}$. Edición), México, D.F., Ed: McGraw-Hill Interamericana, 2006

8. Ives, B And Learmonth, G. The Information Systems as a Competitive Weapon, Communications of the ACM (27:12), December 1984, pp. 1193-1201.

9. Lucas, H.C. The Use of an Accounting Information System, Action and Organizational Performance. The Accounting Review (L: 4), October 1975, pp. 735-746.

10. Mithas, Sunil; Krishnan, M.S; Fornell, Claes. Effect of Information Technology on Customer Satisfaction: Theory and Evidence, Ross School of Business Working Paper Series Working Paper No. 971, June 2005

11. Panko, R. Spending on Office Systems: A Provisional Estimate, Office Technology and People (1:2, 3), September, 1982, pp. 177-194.

12. The PIMS Program. Management Productivity and Information Technology, The Strategic Planning Institute, Cambridge, MA, 1984.

13. Ross, Jeanne and Rockart, John. Reconceptualizing IT, Sloan Management Review (302), January 1999.

14. Strassmann, P. Information Payoff, Free Press, New York, 1985.

15. Turner, J. Organizational Performance, Size and the Use of Data Processing Resources, working paper, \#58, Center for Research in Information Systems, New Cork University, New York, 1985.

16. Turner, J. and Lucas, H.C., Jr. Developing Strategic Information Systems, in Handbook of Business Strategy, W. Guth (ed), Warren, Gorham and Lamont, Boston, 1985, pp.21 / 1 - 21 /35.

17. Weill, Peter. The Relationship Between Investment in Information Technology and Firm Performance in the Manufacturing Sector, unpublished Ph.D. dissertation, New York University, New York, 1988.

18. Weill, Peter; Olson, Magrethe H. Managing Investment In Information Technology: Mini Cases Examples and Implications; MIS Quarterly; Mar 1999; 13, 1; ProQuest Computing.

19. Zammuto, R.F. Assessing Organizational Effectiveness: Systems Change, Adaption and Strategy, State University of New York Press, Albany, NY, 1982.

\section{NOTES}


NOTES 